\title{
Subconjunctival orbital fat prolapse and thyroid associated orbitopathy: a clinical association
}

\author{
This article was published in the following Dove Press journal: \\ Clinical Interventions in Aging \\ 13 February 2017 \\ Number of times this article has been viewed
}

\section{Klio I Chatzistefanou' \\ Christianna Samara ${ }^{2}$ \\ loannis Asproudis ${ }^{3}$ \\ Dimitrios Brouzas' \\ Marilita M Moschos' \\ Elisabeth Tsianta' \\ George Piaditis ${ }^{4}$}

'First Department of Ophthalmology, National and Kapodistrian University of Athens Medical School, Athens, Greece; ${ }^{2}$ Department of Radiology and Endocrinology, ${ }^{3}$ Department of Ophthalmology, University of loannina, loannina, Greece; ${ }^{4} A$ thens General Hospital "G. Gennimatas", Athens, Greece
Correspondence: Klio I Chatzistefanou First Department of Ophthalmology, National and Kapodistrian University of Athens Medical School, 32 Socratous Street, 16673 Voula, Athens, Greece Tel/fax +30 21 8951722

Email kliochat@med.uoa.gr
Background: Thyroid associated orbitopathy (TAO) comprises a spectrum of well-recognized clinical signs including exophthalmos, eyelid retraction, soft tissue swelling, ocular misalignment, keratopathy as well as a number of less common manifestations. Subconjunctival fat prolapse is a rare clinical condition occurring typically spontaneously in elderly patients with a mean age of 65-72 years. We describe subconjunctival prolapse of orbital fat as an uncommon clinical association of TAO.

Materials and methods: Observational study of six patients presenting with a subconjunctival protrusion under the lateral canthus in a series of 198 consecutive cases with TAO examined at a tertiary care referral center.

Results: A superotemporally located yellowish, very soft, freely mobile subconjunctival protrusion developed unilaterally in two and bilaterally in four patients with TAO (incidence $3.03 \%$ ). It was one of the presenting manifestations of TAO in four of ten eyes studied and incited the diagnostic work-up for TAO in two of six patients in this series. Magnetic resonance imaging of the orbit indicated fat density in continuity with intraorbital fat in the area of protrusion. A male to female preponderance of 4:2 and an advanced mean age at onset of TAO is noteworthy for these six patients compared to the pool of 192 patients (64.8 versus 51.8 years, respectively, $P=0.003$ ) not bearing this sign.

Conclusion: Subconjunctival orbital fat prolapse, a clinically impressive age-related ocular lesion, may occasionally predominate amid other clinical manifestations of TAO. It is a nonspecific sign developing most commonly among patients with a relatively advanced age at presentation. Awareness of this association may alert to the diagnosis of thyroid orbitopathy and reassure the patient and physician as to the benign character of the lesion.

Keywords: subconjunctival orbital fat prolapse, elderly, age-related, Graves ophthalmopathy, thyroid associated orbitopathy, autoimmune thyroidopathy

\section{Introduction}

Thyroid associated orbitopathy (TAO) comprises a spectrum of ophthalmic and extraocular manifestations including eyelid retraction, exophthalmos, eyelid and conjunctival edema, extraocular muscle fibrosis and compressive optic neuropathy, resulting from autoimmune stimulation of orbit epitopes, including the adipose tissue and the extraocular muscles. ${ }^{1,2}$

The constellation of these findings may not always be present ${ }^{3}$ and atypical modes of presentation, especially among euthyroid patients, may obviate the diagnosis.

A number of less common features of TAO have been reported in the literature, ${ }^{4-7}$ including superior limbic keratoconjunctivitis and prominent premalar and cheek swelling (Table 1). In this study we report on the finding of a prominent subconjunctival protrusion noted in the lateral canthal area of six patients with TAO and comment on 
Table I Common' and less common or miscellaneous ${ }^{1,6,7}$ signs of thyroid associated orbitopathy and incidence of the most common and well-studied signs

\begin{tabular}{|c|c|c|c|c|c|}
\hline Common signs & Incidence & Less common signs & Incidence & $\begin{array}{l}\text { Miscellaneous } \\
\text { signs }\end{array}$ & Description \\
\hline $\begin{array}{l}\text { Eyelid retraction } \\
\text { (Dalrymple-von Graefe's) }\end{array}$ & $90 \%$ & $\begin{array}{l}\text { Decreased vision (optic } \\
\text { nerve dysfunction) }\end{array}$ & $6 \%$ & Kocher's & $\begin{array}{l}\text { Spasmodic upper lid retraction with visual } \\
\text { fixation }\end{array}$ \\
\hline Exophthalmus & $62 \%$ & Superior limbic & $3.3 \%$ & Boston's & Jerky and uneven movement of upper lid on \\
\hline Ocular misalignment & $43 \%$ & keratoconjunctivitis & & & downward gaze \\
\hline Conjunctival hyperemia & $34 \%$ & Prominent premalar & $1.8 \%$ & Griffith's & Lower lid lag on upward gaze \\
\hline Eyelid edema & $32 \%$ & and cheek swelling & & Means' & Scleral show on upward gaze (globe lag) \\
\hline Conjunctival chemosis & $23 \%$ & & & Joffroy's & Absence of forehead creases on upward gaze \\
\hline \multirow{12}{*}{ Corneal staining } & $10 \%$ & & & Sainton's & Delayed frontalis contraction on upward gaze \\
\hline & & & & Rosenbach's & Trembling of gently closed lids \\
\hline & & & & Stellwag's & Infrequency and incompleteness of blinking reflex \\
\hline & & & & Enroth's & Puffy swelling of lids \\
\hline & & & & Gifford's & Difficulty of eversion of upper lid \\
\hline & & & & Jellinek's & Increased pigmentation of upper lids \\
\hline & & & & Knie's & Unequal pupil dilation in dim light \\
\hline & & & & Cowen's & Jerky pupillary contraction to consensual light \\
\hline & & & & Loewie's & Pupil dilation with weak adrenaline solution \\
\hline & & & & Mobius & Weakness of convergence \\
\hline & & & & Sucker's & Inability to maintain fixation on lateral gaze \\
\hline & & & & Riesman's & Bruit audible over closed eye \\
\hline
\end{tabular}

Notes: Data from Duke-Elder. ${ }^{28}$

the diagnostic significance of this, not previously reported to our knowledge, ${ }^{1,4,5}$ clinical association.

\section{Materials and methods}

We recorded the demographic and clinical characteristics of six consecutive patients who presented with the finding of a temporally located subconjunctival swelling and were diagnosed with TAO.

The study has followed the Tenets of the Declaration of Helsinki and was approved by the Institutional Review Board of Athens General Hospital "G. Gennimatas". In accordance to IRB requirements, patients consented for publication of this case series and the associated images. The sex, age at presentation of the specific sign under study as well as the age at onset of TAO, the age at onset of autoimmune dysthyroidism (when applicable), thyroid and autoimmune status as well as the therapeutic modalities employed were recorded. A complete ophthalmic examination, including visual acuity testing, an orthoptic evaluation, Hertel exophthalmometry and assessment of the clinical activity score, ${ }^{8}$ applanation tonometry and fundoscopy (in selected time points) were performed at the initial and follow-up examinations. Magnetic resonance imaging (MRI) of the orbit was obtained in four patients.

A comparison with the demographic characteristics (age and sex) for the total pool of 192 consecutive patients with TAO not bearing this sign who were examined in the corresponding time period in the same tertiary care referral center was performed using descriptive statistics (independent samples $t$-test, Fisher's exact test).

\section{Results}

The first patient who drew our attention to the diagnostic significance of the superotemporal subconjunctival protrusion was a euthyroid 68-year-old man who was referred by his primary physician with the clinical suspicion of lacrimal gland enlargement in his right eye (patient \#1). Five more patients, three men and two women, with a similar clinical picture and an eventual or preexisting diagnosis of TAO, were prospectively enrolled.

The lesion was located in the temporal or superior temporal quadrant in all six patients and shared the morphology of a convex smooth anterior surface, with the posterior surface disappearing within the fornix and the orbit. It was yellowish to purple-yellow, movable and could be easily repositioned into the orbit by applying direct pressure on it. The protrusion became more easily seen when the upper eyelids were elevated or the eye was rotated medially or downward and increased in size with retropulsion of the globe.

The yellowish hue of the lesion was indicative of fat composition with occasionally visible fat globules. An orbit MRI was performed in four patients and demonstrated fat density in the area of protrusion in continuity with the intraconal fat (Figures 1B, 2D, 3B).

The incidence of this finding in a series of 198 patients with TAO examined by one of us (KIC) in the same tertiary 
care referral center in the corresponding 7-year time period is $3.03 \%$. It developed unilaterally in two patients and bilaterally, albeit asymmetrically, in the other four cases.

The mean age at presentation with TAO symptomatology was $64.8( \pm 6.6)$ years (range 52.5-76) for these six patients compared to $51.8( \pm 14.3)$ for the pool of 192 patients not bearing this sign ( $P=0.003$, independent sample $t$-test $)$. A male to female preponderance of 4:2 was noted in this series compared to approximately $6: 10(73 / 119)$ male to female ratio for the remaining 192 patients with TAO. The difference in the percentage of male patients ( $66.7 \%$ versus $38.02 \%$, respectively) was not statistically significant ( $P=0.210$, Fisher's exact test). One of the female patients (case \#2) who developed this sign at the age of 58 had a markedly obese somatotype.

A history of diplopia and marked ipsilateral proptosis was reported in four patients (cases \#1, 2, 4 and 5). Three patients (cases \#2, 4, 5) developed a severe form of TAO. It is noteworthy that apart from impairing cosmesis, the clinical course of the specific lesion was benign, there was no need for additional therapy other than lubrication of the globe to prevent exacerbation of dry eye symptoms.

A comprehensive outline of TAO findings for each patient is provided in Table 2 .

\section{Report of cases}

\section{Patient I}

A 68-year-old male presented in May 2006 complaining of a visible "mass" protruding under the lateral part of his mildly swollen right upper eyelid and intermittent diplopia.

The "mass" had a yellowish purple hue and was soft and non tender upon palpation. Upper eyelid retraction and restriction of elevation was noted in the right eye (Figure 1A). A systemic work-up for autoimmune dysthyroidism revealed euthyroid status and borderline elevation of anti-TSH

Table 2 Comprehensive outline of clinical features of thyroid associated orbitopathy for each patient

\begin{tabular}{|c|c|c|c|c|c|c|c|c|c|c|c|c|}
\hline TAO features & Case \#I & & Case \#2 & & Case \#3 & & Case \#4 & & Case \#5 & & Case \#6 & \\
\hline Thyroid status at onset & Euthyroid & & Hyperthyroid & & Euthyroid & & Hyperthyroid & & Hyperthyroid & & $\begin{array}{l}\text { Hypothyroid } \\
\text { (in the past) }\end{array}$ & \\
\hline TAO related antibodies & \pm & & + & & + & & + & & + & & No data & \\
\hline Age at presentation, ${ }^{\text {a }}$ sex & 68 , male & & 7I, male & & 76, male & & 72 , male & & 58 , female & & 65 , female & \\
\hline Age at onset (TAO) & 68 & & 66 & & 76 & & 64 & & 52.5 & & 55 & \\
\hline $\begin{array}{l}\text { Age at onset (autoimmune } \\
\text { thyroid disease) }\end{array}$ & - & & 66 & & 76 & & 64 & & 52 & & 50 & \\
\hline VA (R-L) & 1.2 & 1.0 & 0.9 & 0.9 & 1.0 & 1.0 & 0.9 & 1.0 & 1.0 & 1.0 & 1.0 & 1.0 \\
\hline Hertel (R-L), (ICD) ${ }^{\mathrm{b}}$ & $\begin{array}{l}26 \\
(98 \mathrm{~mm})\end{array}$ & 21 & $\begin{array}{l}19 \\
(98)\end{array}$ & $17^{c}$ & $\begin{array}{l}23 \\
(105)\end{array}$ & 24 & $\begin{array}{l}21 \\
(95)\end{array}$ & 21 & $\begin{array}{l}30 \\
(105)\end{array}$ & 30 & $\begin{array}{l}22.5 \\
(95)\end{array}$ & 23.5 \\
\hline Lid retraction (R-L) & + & - & + & - & + & + & + & + & + & + & - & - \\
\hline \multicolumn{13}{|l|}{ Soft tissue (R-L) } \\
\hline $\begin{array}{l}\text { Lid edema } \\
\text { Conjunctival }\end{array}$ & + & - & + & + & + & + & + & + & + & + & + & + \\
\hline Hyperemia & + & - & + & + & - & - & - & - & - & - & - & - \\
\hline Edema & + & - & & & & & & & - & - & - & - \\
\hline $\mathrm{CAS}^{\mathrm{c}}$ & $4 / 7$ & & $2 / 7$ & & $\mathrm{I} / 7$ & & $\mathrm{I} / 7$ & & $5 / 7$ & & $1 / 7$ & \\
\hline Cover test, primary gaze & I5 LHT & & Orthotropia ${ }^{c}$ & & Orthotropia & & $\begin{array}{l}50 \text { LHT, } \\
20 \text { LET }\end{array}$ & & $\begin{array}{l}40 \mathrm{LHT} \\
14 \mathrm{LXT}\end{array}$ & & Orthotropia & \\
\hline EOM involvement (MRI) & IR, MR OD & & IR, MR OU & & IR, MR OU & & $\begin{array}{l}\text { SR, MR, LR } \\
\text { OU }\end{array}$ & & $\begin{array}{l}\text { SR, MR, IR, } \\
\text { LR OU }\end{array}$ & & No data & \\
\hline Optic neuropathy & - & & $--^{c}$ & & - & & - & & - & & - & \\
\hline \multicolumn{13}{|l|}{ Anterior fat prolapse } \\
\hline Laterality & Unilateral & & $\begin{array}{l}\text { Bilateral } \\
\text { symmetric }\end{array}$ & & $\begin{array}{l}\text { Bilateral } \\
\text { asymmetric }\end{array}$ & & $\begin{array}{l}\text { Bilateral } \\
\text { asymmetric }\end{array}$ & & Unilateral & & Bilateral & \\
\hline \multicolumn{13}{|l|}{ Symmetry } \\
\hline Follow-up (months) & 44 & & 26 & & 15 & & 14 & & 7 & & 6 & \\
\hline Treatment for TAO & $\begin{array}{l}\text { IV + oral } \\
\text { steroids }\end{array}$ & & $\begin{array}{l}\text { Orbit decom } \\
\text { pression, } \\
\text { strabismus surgery }\end{array}$ & & - & & IV steroids & & $\begin{array}{l}\text { IV steroids } \\
\text { Somatostatin } \\
\text { analogs }\end{array}$ & & $\begin{array}{l}\text { Oral } \\
\text { steroids }\end{array}$ & \\
\hline
\end{tabular}

Notes: a Age at presentation for evaluation of the finding of lateral subcanthal protrusion. ${ }^{b}$ Hertel exophthalmometry. ${ }^{c}$ Measurements shown in table correspond to clinical parameters encountered upon presentation with the specific lesion under study.

Abbreviations: TAO, thyroid associated orbitopathy; R-L, right eye-left eye; CAS, clinical activity score; VA, visual acuity (decimal scale); LHT, left hypertropia (prism diopters, primary position); LET, left esotropia (prism diopters, primary position); LXT, left exotropia (prism diopters, primary position); EOM, extraocular muscle; OD, right eye; OS, left eye; OU, both eyes; SR, superior; IR, inferior; MR, medial rectus; LR, lateral rectus; IV, intravenous; ICD, intercanthal distance (mm); MRI, magnetic resonance imaging. 

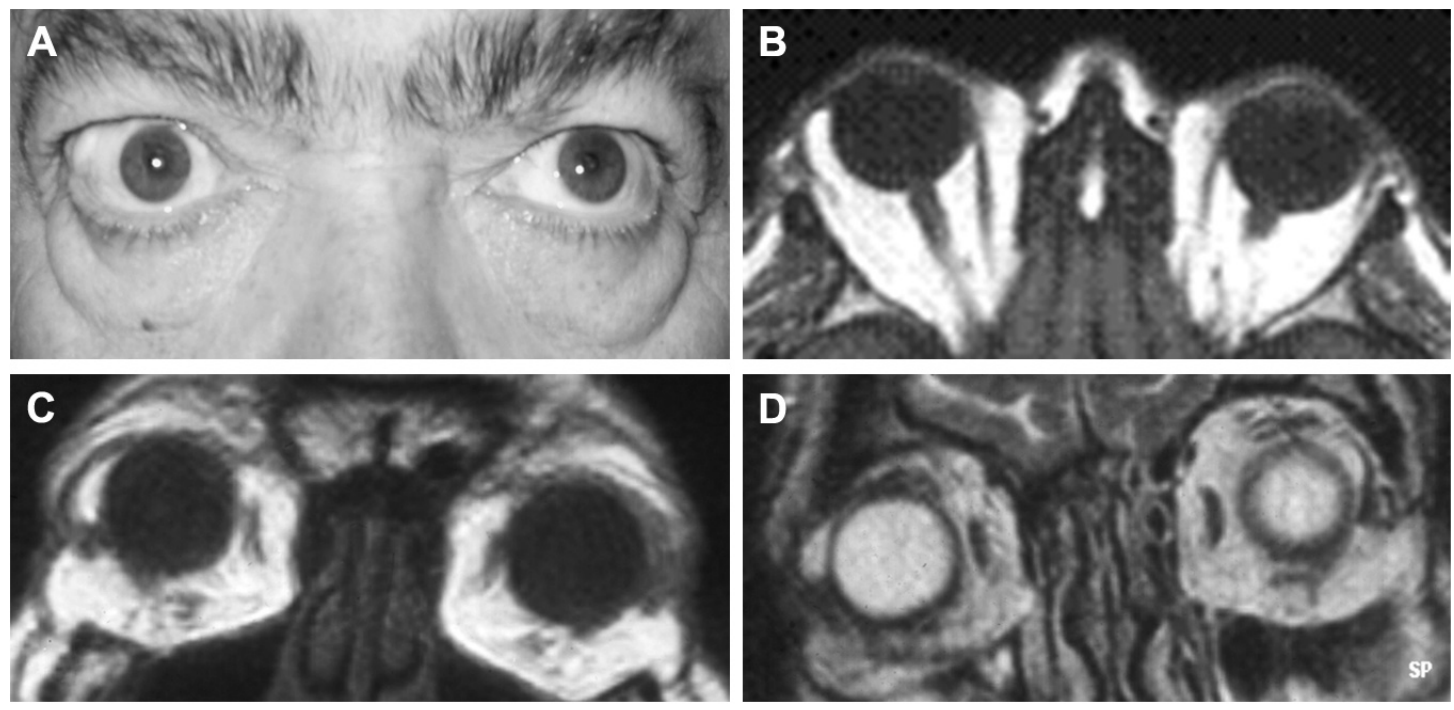

Figure I (A) Patient I with subconjunctival fat prolapse noted superotemporally in the right eye. (B) TI weighted spin echo (SE) transverse scan shows anterior fat prolapse in the temporal quadrant in the right eye. (C) and (D): TI weighted and T2 weighted (respectively) Spin Echo coronal scans depicting fat protrusion in the area of the clinically visible bulge.

receptor antibodies: $8.8(\mathrm{nl}<9$, sensitivity 0.8$)$. The diagnosis of euthyroid Graves orbitopathy was established based on the typical constellation of ipsilateral proptosis, eyelid retraction, lid and conjunctival edema as well as tendon sparing enlargement of right inferior and medial rectus muscles. An orbit MRI outlined anterior herniation of intraorbital fat (Figure 1B-D) with slight displacement of the lacrimal gland temporally in the involved right orbit as opposed to normal appearance of the lacrimal gland on the left side.

He was treated with intravenous and oral steroids with partial resolution of exophthalmos and diplopia. The prolapse did not cause any symptoms and remained unchanged after 44 months of follow-up time.

\section{Patient 2}

A 55-year-old obese woman was first examined in March 2006 complaining of diplopia and unilateral exophthalmos in the left eye (Figure 2A and B). She reported a 2.5-year long history of TAO in the context of Graves disease, poorly responsive to intravenous methylprednisolone regimens.

She returned 3 years later with a recent onset of symptoms in the previously not involved right eye. She was particularly
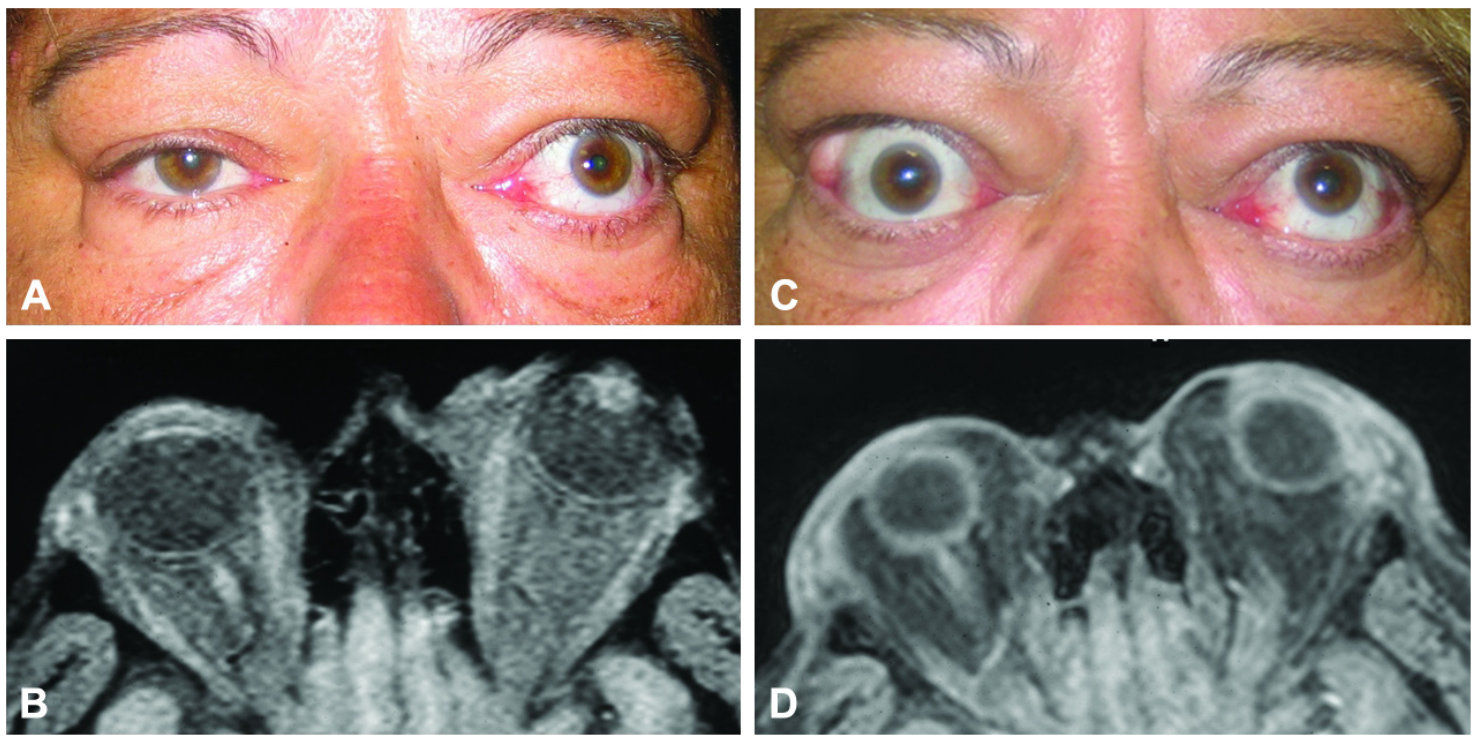

Figure 2 (A) Patient 2, thyroid ophthalmopathy associated signs involving the left eye primarily and corresponding (B) TI weighted transverse fat suppressed magnetic resonance imaging scan. (C) Same patient, 3 years later, new-onset thyroid ophthalmopathy is noted in the right eye with prominent temporal subconjunctival fat prolapse and corresponding TI weighted transverse fat suppressed scan; (D) showing orbital fat prolapsing anteriorly, anterior bowing of the orbital septum and lateral displacement of the lacrimal gland. 
concerned about the emergence of a soft "lump" in the outer part of the recently involved right eye. Exophthalmos, eyelid retraction and the presence of a soft lump under the eyelid protruding above the lateral canthus were noted in the right eye (Figure 2C). The lesion was soft upon palpation and persisted unchanged after a 7-month follow-up time despite gradual stabilization of thyroid levels. An orbit MRI showed orbital fat prolapsing anteriorly, anterior bowing of the orbital septum and lateral displacement of the lacrimal gland which looked smaller in the involved orbit as opposed to normal size and appearance of the lacrimal gland in the contralateral left orbit (Figure 2D).

\section{Patient 3}

A 72-year-old man presented in October 2008 complaining of a yellowish bulge protruding under the upper eyelid of both eyes for the past 6 months and a gradually worsening "swelling" of his eyes. Clinical and paraclinical testing revealed hyperthyroidism and signs of Graves orbitopathy. An orbit MRI revealed excess orbital fat herniating anteriorly (Figure 3). The lacrimal gland on either side was identified in place and was of normal size. He was followed for 15 months, during that time thyroid levels stabilized, without an improvement in the size of the lesion.

\section{Patient 4}

A 72-year-old man presented in November 2008 with pronounced ocular misalignment and a conjunctival protrusion under both upper eyelids. He had been diagnosed with autoimmune hyperthyroidism 8 years before. Orbit MRI showed anterior herniation of orbital fat with the lacrimal
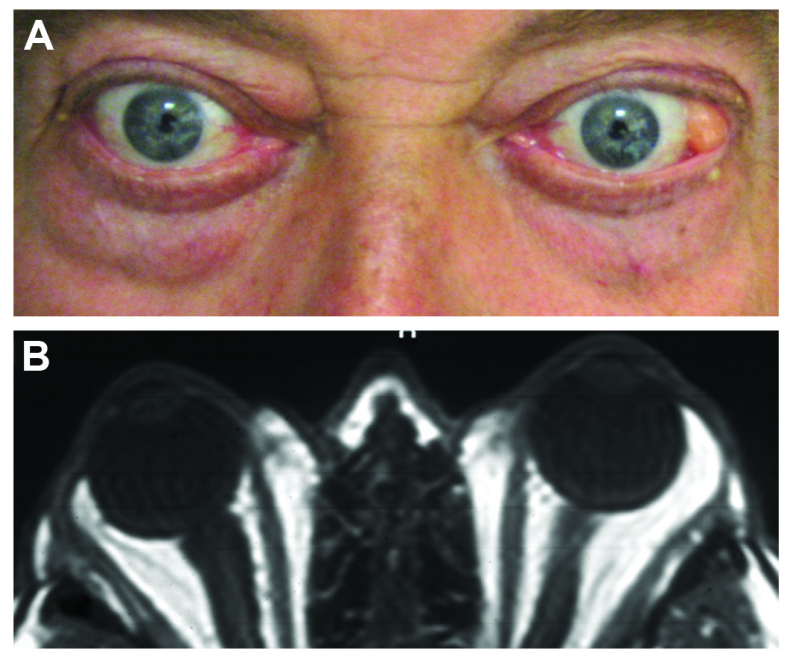

Figure 3 (A) Patient 3, asymmetric bilateral subconjunctival fat prolapse is most notable in the left eye. (B) TI weighted spin echo (SE) coronal scan shows anterior herniation of intraconal fat in the temporal quadrants. gland identified at the normal position and size (Figure 4A). The patient declined strabismus surgery and has been followed for 20 months with no change in the clinical picture.

\section{Patient 5}

A 71-year-old man presented in November 2007 complaining of a "mass" like protrusion under the lateral part of both upper eyelids for the last several months (Figure 4B). He had previously undergone orbit decompression and strabismus surgery in both eyes elsewhere for TAO diagnosed 5 years before, confirmed with past orbit MRI scans. The lesion had a light purple-yellow hue (Figure 4C and D) and was soft and non tender upon palpation.

\section{Patient 6}

A 65-year-old woman presented in October 2010 for evaluation of a melanocytic lesion on her right upper eyelid. She reported a long history of hypothyroidism and bilateral exophthalmos, upon remission at the time of presentation. Asymmetric bilateral subconjunctival temporal protrusions were noted (Figure 4E) which by history had emerged shortly after the onset of TAO. There was no change in the clinical picture after 5 months' follow-up time.

\section{Discussion}

Schmack et $\mathrm{al}^{9}$ in their comprehensive study of histopathological findings of subconjunctival herniated orbital fat noted that 2 of 17 patients in their series had a history of endocrine orbitopathy. Saban et a ${ }^{10}$ noted that 2 of 27 patients submitted to surgical treatment for subconjunctival fat prolapse had a history of Graves ophthalmopathy. The high prevalence derived from these reports ( $11.7 \%$ and $7.4 \%$, respectively) may suggest an association between subconjunctival fat prolapse and TAO.

From the clinical standpoint, subconjunctival prolapse of orbital fat accompanied the presentation of active thyroid eye disease in four of the ten eyes reported in this series (cases \#1, \#2, right eye and \#3) and was by simple inspection an impressive enough finding to draw the internist's and ophthalmologist's attention to initiate the work-up that led to the diagnosis of TAO and autoimmune dysthyroidism.

The prolapse developed subsequently in the course of autoimmune orbitopathy in the other three cases. The patients presented with concern about the new finding of a "mass like" lesion in the "outer part of the eye".

Orbital fat is located within the intraconal and extraconal space and is contained by Tenon's capsule, periorbita and orbital septum. Tenon's capsule is a thin membrane that envelops the eyeball, separating it from fat. It extends 

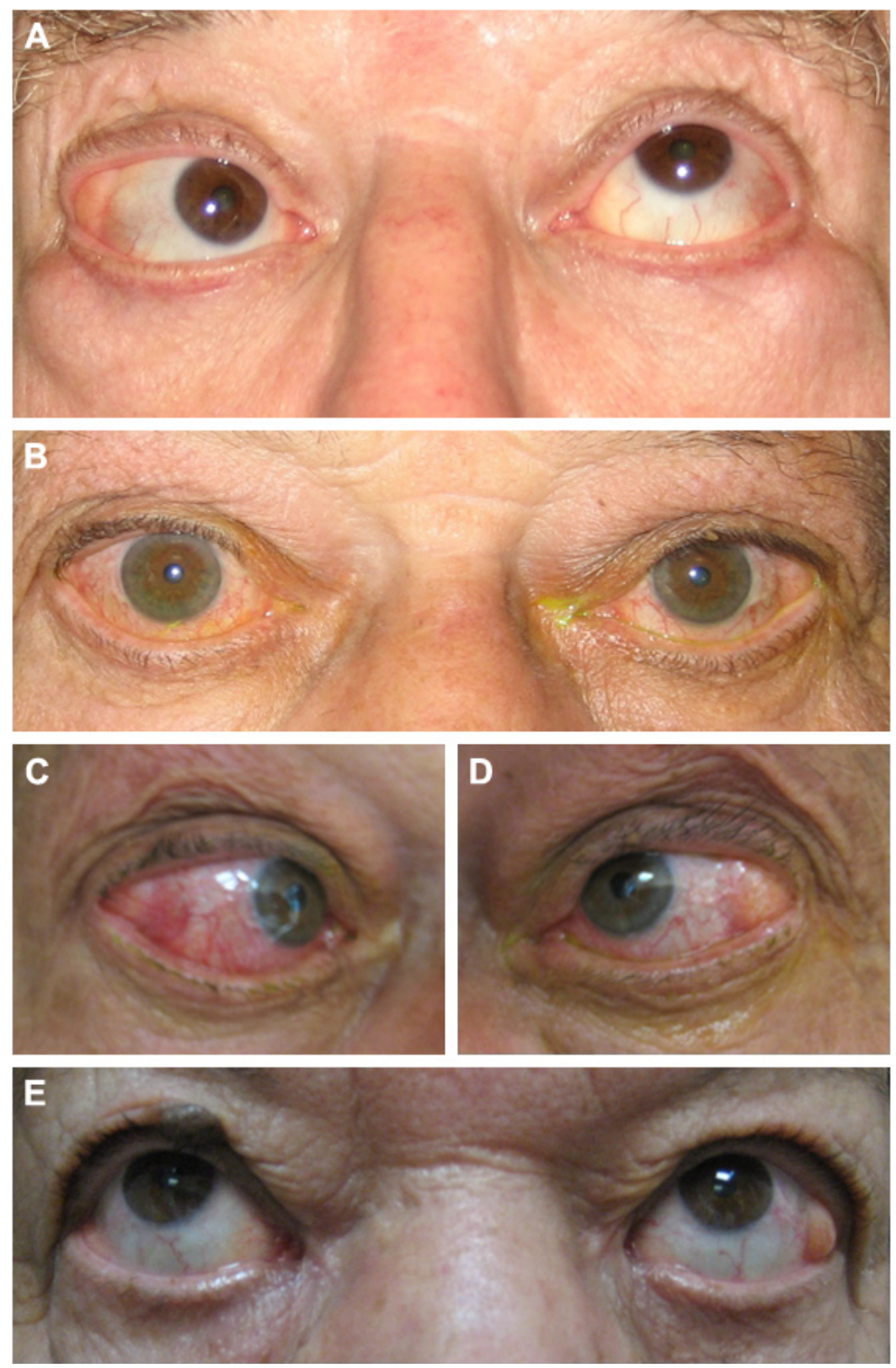

Figure 4 (A) Patient 4, pronounced ocular misalignment and bilateral asymmetric subconjunctival fat prolapse with a superotemporal "fat pad" most notable in the right eye. (B) Patient 5 with longstanding TAO and bilateral subconjunctival fat prolapse. (C and D) Same patient, right and left eye, respectively in adduction with close magnification of the lesion highlighting yellowish hue compatible with fat composition. (E) Patient 6 with past history of TAO, asymmetric temporal subconjunctival fat prolapse. Abbreviation: TAO, thyroid associated orbitopathy.

from the limbus of the cornea anteriorly, to the optic nerve posteriorly and is pierced by the tendons of the extraocular muscles.., 11

Despite its support, orbital fat has the tendency to migrate under the influence of gravity and pressure. Any mechanism (eg, aging, surgery, trauma, disease) resulting in breaching of the surrounding connective tissue allows a forward movement of the orbital fat into either the subconjunctival space (intraconal fat) or the eyelids (extraconal fat). ${ }^{12-15}$

In contrast to prolapsed extraconal fat causing the well-known palpebral bags which is a common finding in elderly patients, subconjunctival intraorbital fat herniation is a rare clinical condition attributed to trauma or surgery ${ }^{16}$ or occurring spontaneously, ${ }^{17}$ typically in elderly male patients with a mean age of 65-72 years (range, 28-94 years). ${ }^{12}$

It typically occurs in the lateral canthal area beneath the temporal or superotemporal bulbar conjunctiva as a soft yellowish mass with a convex anterior margin and faint superficial blood vessels..$^{14,15,17-20}$ It is usually bilateral, but may also be unilateral. As the extension of prolapsed fat is often asymmetric, minor lesions in the contralateral eye may be sometimes overlooked. ${ }^{11}$ 
The pathogenesis of spontaneous subconjunctival fat prolapse is believed to be associated with an age-related acquired local attenuation of Tenon's capsule, ${ }^{14}$ allowing the fat from the intraconal space to move forward and appear clinically as a subconjunctival mass. ${ }^{13,18}$

The relative contribution of raised intraorbital pressure in facilitating anterior prolapse of orbital fat has not been appreciated so far. We postulate that the raised intraorbital pressure and increase in orbital fat characteristic of TAO may predispose to anterior herniation of intraorbital fat. ${ }^{21}$ It is reasonable that this mechanism may underlie the concurrent presentation of active TAO and subconjunctival fat prolapse in four patients in this series as well as an increased prevalence of this lesion among TAO patients in general. It is of note that exophthalmos and lid swelling, to mention only two of the most common signs of Graves ophthalmopathy, are not specific for this disease either.

Although subconjunctival fat prolapse is reported in case reports $^{13,20}$ or small case series ${ }^{12,14,15,17,18}$ as a rare entity, there are no data in the literature accessible to us on its incidence in the general population to compare with the $3.03 \%$ rate we noted among our TAO patients. The clinical manifestations of TAO may be encountered at variable frequencies ranging from $92 \%$ of patients developing upper eyelid retraction during the course of their disease to $3.3 \%$ developing superior limbic keratoconjunctivitis in the large prospective study by Bartley. ${ }^{1}$ Less common signs, such as prominent malar and cheek swelling have been recognized in $1.8 \%$ of TAO patients in another series ${ }^{7}$ (Table 1). Bartley and Gorman noted that only $5 \%$ of patients with TAO have the complete constellation of the so-called classic findings: eyelid retraction, exophthalmos, optic nerve dysfunction, extraocular muscle involvement and hyperthyroidism. The diagnosis may be difficult in the absence of thyroid dysfunction and should rely on the combination of certain clinical features. Subconjunctival fat prolapse brought two of our patients (case $\# 1$ and \#3) to medical attention initiating the work-up that led to the diagnosis of TAO; this underscores its potential value in increasing the index of suspicion for the diagnosis of TAO and hyperthyroidism.

It is of note that despite the fact that it proved to be a quite impressive, and sometimes presenting clinical manifestation of TAO, it was not an isolated sign of TAO in any of our patients. Based on these remarks, we suggest that if a substantial amount of orbital fat prolapse is noted, the clinician should check carefully for other signs of TAO and the diagnosis of autoimmune dysthyroidism should be kept in mind.

From the ophthalmologist's perspective, the differential diagnosis may include lacrimal gland prolapse or enlargement, dermolipoma, subconjunctival and orbital lipomas and lymphoma. ${ }^{14,16,21-24}$

The differential diagnosis with a lacrimal gland mass which may also be associated with exophthalmos, inferomedial globe displacement and fullness of the eyelid (common signs of TAO, see patient \#1 in this series) is of particular importance given the morbidity of lacrimal gland tumors. Enlargement of the palpebral lobe of the lacrimal gland by inflammation, infiltration or tumor produces a palpable solid mass in the superotemporal portion of the orbit and imaging findings of lacrimal gland enlargement sometimes in association with bone molding or destruction. Orbit MRI identified the lacrimal gland in a posterior and laterally displaced position (Figure 2D) in our patient.

Overall subconjunctival fat prolapse may easily be distinguished ${ }^{25}$ by clinical inspection and palpation alone based on its characteristic softness, being readily indented or moved by a cotton-tip applicator. Computed tomography and MRI are definitively helpful when in doubt, showing the continuity between the prolapsed fat and the intraconal fat.

Except for the cosmetic blemish, the lesion caused no major symptomatology, hence required no treatment and no histopathological examination in our patients. Whenever judged necessary, surgical excision of fat under local anesthesia has been suggested in the literature as a safe and effective means for treating these lesions ${ }^{12-14,16,21,24-27}$ with a low recurrence rate after local excision., ${ }^{9,10,25}$

\section{Conclusion}

Based on data from this series, subconjunctival fat prolapse may be an uncommon, not isolated, but clinically impressive part of the clinical picture of TAO developing primarily among male patients with an advanced age at presentation. Awareness of this association may alert to the diagnosis of thyroid dysfunction and reassure the patient and physician as to the benign character of the lesion.

\section{Disclosure}

The authors report no conflicts of interest in this work.

\section{References}

1. Bartley GB, Fatourechi V, Kadrmas EF, Jacobsen SJ, Ilstrup DM, Garrity JA, Gorman CA. Am J Ophthalmol. 1996;121:284-290.

2. Wiersinga WM, Bartalena L. Epidemiology and prevention of Graves' ophthalmopathy. Thyroid. 2000;12(10):855-860.

3. Bartley GB, Gorman CA. Diagnostic criteria for Graves' ophthalmopathy. Am J Ophthalmol. 1995;119(6):792-795.

4. Jakobiec FA, Jones IS. Orbital inflammations. In: William T, Jaeger E, editors. Duane Clinical Ophthalmology. Philadelphia: Lippincott Raven; 1996;35:22. 
5. Netland PA, Dallow RL. Thyroid ophthalmopathy. In: Albert DM, Jakobiec FA, editors. Principles and Practice of Ophthalmology.1st ed. Philadelphia PA: WB Saunders; 1994:2937-2955.

6. Kadrmas EF, Bartley GB. Superior limbic keratoconjunctivitis. A prognostic sign for severe Graves ophthalmopathy. Ophthalmology. 1995;102(10): 1472-1475.

7. Kim BJ, Kazim M. Prominent premalar and cheek swelling: a sign of thyroid-associated orbitopathy. Ophthal Plast Reconstr Surg. 2006; 22(6):457-460.

8. Mourits MP, Prummel MF, Wiersinga WM, Koorneef L. Clinical activity score as a guide in the management of patients with Grave's ophthalmopathy. Clin Endocrinol (Oxf). 1997;47(1):9-14.

9. Schmack I, Patel RM, Folpe AL, et al. Subconjunctival herniated orbital fat: A benign adipocytic lesion that may mimic pleomorphic lipoma and atypical lipomatous tumor. Am J Surg Pathol. 2007;31(2): 193-198.

10. Saban M, Weijtens O, van den Bosch W, Paridaens D. Efficacy of transconjunctival excision of orbital fat prolapse: a long-term follow-up study. Acta Ophthalmol. 2014;92(3):291-293.

11. Koorneef L. New insights in the human orbital connective tissue. Result of a new anatomic approach. Arch Ophthalmol. 1977;95(7): 1269-1273.

12. Glover AT, Grove AS Jr. Subconjunctival orbital fat prolapse. Ophthal Plast Reconstr Surg. 1987;3(2):83-86.

13. Jordan DR. Orbital fat prolapse. Arch Ophthalmol. 1993;111(11):1583.

14. McNab AA. Subconjunctival fat prolapse. Aust $N Z J$ Ophthalmol. 1999;27(1):33-36.

15. Monner J, Benito JR, Zayuelas J, Paloma V, Castro V, Serra JM. Transconjunctival herniation of orbital fat. Ann Plast Surg. 1998; 41(6):658-661.

16. Parks MM. Ocular Motility and Strabismus. Chapter 1. Extraocular muscles. Hagerstown MD: Harper and Row; 1975:1-6.

17. Jordan DR, Tse DT. Herniated orbital fat. Can J Ophthalmol. 1987;22(3): $173-177$.
18. Stangos AN, Hamédani M. Spontaneous subconjunctival orbital fat prolapse: presentation of four cases. Klin Monbl Augenheilkd. 2006; 223(5):415-417.

19. Kim E, Kim HJ, Kim YD, Woo KI, Lee H, Kim ST. Subconjunctival fat prolapse and dermolipoma of the orbit: differentiation on CT and MR imaging. AJNR Am J Neuroradiol. 2010;32(3):465-467.

20. Masoud MT, Shaikh MY. Images in clinical medicine. Subconjunctival swelling - prolapse of orbital fat. N Engl J Med. 2007;356(1):67.

21. Chang E, Wilson MW, Smith ME. Orbital imaging in thyroid eye disease. In: Dutton JJ, Haik BG, editors. Thyroid Eye Disease. New York: Marcel Dekker, Inc; 2002:303.

22. Offret H, Labetoulle M, Frau E. Hernies graisseuses sous-conjonctivales de l'orbite [Subconjunctival adipose hernias of the orbit]. J Fr Ophtalmol. 1997;20(8):614-618. French.

23. McNab AA, Wright JE, Caswell AG. Clinical features and surgical management of dermolipomas. Aust N Z J Ophthalmol. 1990;18(2): $159-162$.

24. Daniel CS, Beaconsfield M, Rose GE, Luthert PJ, Heathcote JG, Clark BJ. Pleomorphic lipoma of the orbit: a case series and review of the literature. Ophthalmology. 2003;110(1):101-105.

25. Wang X, Yan J. Subconjunctival orbital fat prolapse: an unsuspecting rare lesion. J Craniofac Surg. 2015;26(2):e92-e94.

26. Sato K, Yamaguchi T, Yokota H. A surgical technique with connective tissue repair for the management of subconjunctival orbital fat prolapse. Clin Exp Ophthalmol. 2006;34(9):841-845.

27. Sniegowski MC, Kelmenson A, Gregory DG, Durairaj VD. Smallincision, sutureless repair of subconjunctival fat prolapse. Ophthal Plast Reconstr Surg. 2012;28(3):221-223.

28. Duke-Elder S. Orbital involvement in general disease. In: System of Ophthalmology, vol XIII. London; Henry Kimpton Publishers. 1974:940-944.
Clinical Interventions in Aging

\section{Publish your work in this journal}

Clinical Interventions in Aging is an international, peer-reviewed journal focusing on evidence-based reports on the value or lack thereof of treatments intended to prevent or delay the onset of maladaptive correlates of aging in human beings. This journal is indexed on PubMed Central, MedLine,

\section{Dovepress}

CAS, Scopus and the Elsevier Bibliographic databases. The manuscript management system is completely online and includes a very quick and fair peer-review system, which is all easy to use. Visit http://www.dovepress. com/testimonials.php to read real quotes from published authors. 